\title{
2-Sübstitüeoksazolo (4,5-b) piri din Türevlerinin Yapı-Etki İlişkileri Üzerinde Araştırmalar
}

\author{
Investigations on The Structure-Activity Relationship of
} 2-Substitutedoxazolo (4,5-b) pyridine Derivatives

\section{Seçkin ÖZDEN* Ismail YALÇIN*}

\section{ÖZET}

Bu çalışmada daha önce sentezi yapılan 12 adetoksazolo $(4,5-b)$ piridin türevinin (1), biyolojik etkileri saptanmış ve hidrofobik parametrelerle yapı ile etkileri arasında ilişki kurulmaya çalışılmıştır.

Türevlerde, biyolojik etki olarak ele alınan antihistaminik etki şiddeti, Magnus tekniğine göre, $0.1 \gamma$ histaminin oluşturduğu kontraksiyonu inhibe eden molar konsantrasyonların bulunması şeklinde saptanmıştır. 2-n-Hekziloksazolo (4,5-b) piridin türevi en etkili bileşik olarak bulunmuştur $\left(1.3 \times 1\left(10^{-7} \mathrm{~mol} / \mathrm{ml}\right.\right.$ si, \% 53 inhibisyonu sağlamaktadır).

Bütün bileşiklerin dağılma katsayıları, 1-oktanol/su (Tampon çözelti, pH: 7.8), $\mathrm{R}_{\mathrm{M}}$ değerleri ise; sabit faz 1-oktanol, hareketli faz aseton/su (Tampon çözelti, pH: 7.8) (30/70) solvan sistemi kullanılarak saptanmıştır.

Bileşiklerin biyolojik etkileri ile dağılma katsayıları ve $R_{M}$ değerleri kullanılarak yapı-etki ilişkileri incelendiğinde, biyolojik etki ile kullanılan bu fizikokimyasal parametreler arasında doğrusal bağıntı olduğu bulunmuştur.

\section{SUMMARY}

This study is an extention of our previous one which twelve 2substitutedoxazolo (4,5-b) pyridine compounds were synthesized 
(1). In this research, the relation between the chemical structures and biological activities of these compounds were investigeted.

The biological activity of all compounds were determined by Magnus method with guinea pig ileum in isolated organ bath. The molar concentration of the compounds which inhibited the ileum contraction as $53 \%$ induced by $0.1 \gamma$ histamine were determined.

Partition coefficients were determined by using 1-octanol/water (Buffer Solution, pH: 7.8), $\mathrm{R}_{\mathrm{M}}$ values were determined by using 1-octanol (Stationary Phase), acetone/water (Buffer Solution, pH: 7.8). (30:70) (Mobile Phase) as solvent systems.

The quantitative relation between the biological activity and the physicochemical properties which were mentioned above were studied and the good correlations were obtained.

\section{Anahtar Kelimeler:}

(2-Sübstitüeoksazolo (4,5-b) piridin, Log P, RM, Yap1 - Etki ilişkileri)

Günümüze kadar oksazolopiridin türevleri üzerinde fizikokimyasal özellikler ele alınarak yapılan herhangi bir yapı-etki çalışmasına rastlanılmamıştır. Ancak oksazolopiridinlerin genellikle 2. konumdan sübstitüe türevlerinin hazırlandığı ve 2 . konumda yer alan grupların etkiyi yönlendirdiği, ayrıca oksazolo (4,5-b) piridin türevlerinin diğer izomerlere oranla daha çok incelendiği dikkati çekmektedir. Bu nedenle araştırma konusu olarak oksazolo (4,5-b) piridin halka sistemi seçilerek, bunun yalnız 2. konumdan sübstitüe türevleri hazırlanmıştır (1). Bu sübstitüentlerin biyolojik etkiye katkılarının, logaritmik dağılma katsayıları $(\log \mathrm{P}), \mathrm{R}_{\mathrm{M}}$ gibi hidrofobik değişmezler yardımıyla olabileceği saptanarak bir yoruma gidilmesi amaçlanmıştır.

Oksazolo (4,5-b) piridin halkasının 2. konumunda gerçekleştirilen sübstitüsyon, homolog bir dizi içinde, düz zincirli alkil grupları ve bunların dallanmış şekilleri ile yapılmıştır. Ayrıca moleküldeki uzaysal değişikliklerin ne ölçüde etkin olduğunu anlayabilmek için düz zincirli gruplarla aynı sayıda karbon atomu içeren doymuş halkalı izomerlerinin de diğerleri ile karşılaştırılması planlanmıştır. 
Sentez edilen bileşiklerin, antienflamatuvar, analjezik ve antipiretik etki gösterecekleri düşünülmektedir $(2,3)$. Bu etkilerin mekanizması henüz kesin olarak açıklanmış değildir. Ancak histamin ve serotonin gibi bazı endojen maddelerin, enflamasyon ve ağrı mediyatörleri olduğu ileri sürülmektedir. Bu görüşten hareketle sentezlenen bileşiklerin histamin reseptörleri üzerinde etki gösterebileceği düşünülmüştür. Ayrıca benzer halka sistemi içeren bazı bileşiklerde de antihistaminik etkinin bulunması bu düşünceyi kuvvetlendirmiştir (4). Bu nedenle, sentezi yapılan bileşiklerin biyolojik etkileri, Magnus tekniğine göre incelenmiş ve bütün türevlerde nicel olarak etkileri saptanmiştır.

\section{DENEL KISIM}

\section{Materyal;}

Bu çalışmada, aseton, eter, 1-oktanol, potasyum dihidrojen fosfat, disodyum hidrojen fosfat (Merck) ve kiselgel HF H $_{4}$ (Camag) kullanılmıştır.

Elektronik alet olarak, Ultraviyole spektrofotometresi (Pye Unicam SP 1700) kullanılmıştır. Doğru denklemleri ise, Altos ACS 8000/2 mikro bilgi sayarından yararlanılarak bulunmuştur.

\section{Metod: Bileşiklerde Biyolojik Etkinin Saptanması:}

Bu çalışmada, bileşiklerin biyolojik etkileri, Magnus tekniğine göre, izole organ banyosunda kobay ileumu ile çalışılarak saptanmış$\operatorname{tir}(4,5,6)$.

Türevlerin etki şiddeti, $0.1 \gamma$ histaminin oluşturduğu kontraksiyonu \% 53 oranında inhibe eden konsantrasyonları bulunarak ortaya konulmuştur (Tablo 1).

Magnus tekniğine göre, biyolojik etkinin saptanmasında iki ön hazırıı̆ı̀ yapılması gerekmektedir:

A) Sentezi yapılan maddelerin çözeltilerinin hazırlanması.

Oksazolopiridin türevleri tuzlan halinde dayanıklı olmadıklarından, bu çalışmada sentez edilen bileşiklerin tuzları yapılamamıştır (7). Bu nedenle, biyolojik etkinin saptanmasında, sudaki çözeltileri yerine, \% 40 lık etanoldeki çözeltileri kullanılmıştır. 
B) Thyrode çözeltisinin hazırlanması (8)

a) 8 g Sodyum klorür, 0.2 g potasyum klorür, $0.1 \mathrm{~g}$ magnezyum klorür, 1 g sodyum bikarbonat, $0.05 \mathrm{~g}$ sodyum dihidrogen fosfat ve 1 g glukoz tartılıp su ile çözülerek 1 lit ye tamamlandı.

b) 0.2 g kalsiyum klorür tartılıp, su ile çözülerek 1 lit ye tamamland1.

a ve b çözeltilerinden eşit miktarda karıştırılarak kullanıldı.

\section{Deneyin Yapılışı:}

İzole organ banyosuna yerleştirilen kobay ileumu $0.1 \gamma$ histamin çözeltisi ile kastırıldı ve kontraksiyon değeri kimonografa çizdirildi. İleum, Thyrode çözeltisi ile üç kez yıkanarak histaminin etkisi giderildi. 3 Dakika beklendikten sonra ileuma standart deneme için \% 40 lık etanol çözeltisi verildi. 10 Dakika sonra tekrar 0.1 histamin verilerek ileumdaki kontraksiyon değeri kimonografa çizdirildi. Böylece etanol çözeltisinin kontrakiyonu ne ölçüde inhibe ettiği belirlendi. İleum, alkol ve histamin çözeltilerinin etkisinden kurtarılmak için üç kez Thyrode çözeltisi ile yıkanarak, 10 dakika beklendi. Daha sonra etkisi gözlenmek istenen bileşiğin \% 40 l1k etanoldeki çözeltisinden ileuma verilerek 10 dakika etki altında bırakıldı. Sürenin bitiminde tekrar $0.1 \gamma$ histamin tatbik edilerek, ileumdaki kontraksiyon kimonografa çizdirildi. Bu şekilde her madde için aynı işlemler tekrarlandı. Tüm türevlerin histaminin kontraksiyonunu \% 53 oranında inhibe eden molar konsantrasyonları saptandı ve bulunan değerlerin ortalamasi alındi.

Bileşiklerin Dağılma Katsayılarının Saptanması: Türevlerin dağılma katsayılarının tayininde, yă fazı olarak 1-oktanol, su fazı olarak ise, disodyum hidrojen fosfat-potasyum dihidrojen fosfat tampon sistemi (pH: 7.8) kullanıldı (9-13).

Tampon çözeltinin hazırlanışı: $20.4 \mathrm{~g}$ Potasyum dihidrojen fosfat, $53.72 \mathrm{~g}$ disodyum hidrojen fosfat, $12 \mathrm{H}_{3} 0$ tartılarak ayrı ayrı su ile 1 lit ye tamamlandı. Böylece her birinden 0.15 Molar çözelti hazırlanmış oldu. $250 \mathrm{ml}$ Tampon çözelti hazırlamak için $0.15 \mathrm{M}$ potasyum dihidrojen fosfat çözeltisinden $49.0 \mathrm{ml}, 0.15 \mathrm{M}$ disodyum hidrojen fosfat çözeltisinden de $201.0 \mathrm{ml}$ alınarak karıştırıldı ve çözeltinin pH si pH metrede ölçülerek 7.8 bulundu. 
Hazırlanan tampon çözelti ile 1-oktanol karışımı (1/1) (v/v), ayırma hunisinde birbiri içinde doyurularak oktanol ile doymuş tampon çözelti, tampon ile doymuş oktanol elde edildi. Hazırlanan bu çözeltiler tüm log $P$ çalışmalarında kullanıldı.

\section{Deneyin yapılışı:}

Balonjoje içinde $10 \mathrm{mg}$ civarında tam tartılmış bileşik 1-oktanol içinde çözülerek $50 \mathrm{ml}$ ye tamamlandı. Bu çözeltiden $10 \mathrm{ml}$ alınıp, kapaklı bir erlenmayer içinde $10 \mathrm{ml}$ tampon çözelti ile $37^{\circ} \mathrm{C}$ lik su banyosunda, manyetik karıştırıcı ile 1 saat 1 sıtıldi. Bu süre sonunda, çözelti santrifüj edilerek oktanol ve su tabakaları ayrıldı. Oktanol tabakasından $1 \mathrm{ml}$ alınarak 1 -oktanol ile $20 \mathrm{ml}$ ye tamamland 1 (A).

Standart çözeltiler, deneyin başında $50 \mathrm{ml}$ lik balon joje içinde hazırlanan çözeltiden $1 \mathrm{ml}$ alınıp, 1-oktanol ile ayrı ayrı 20, 30, 40 ml ye tamamlanarak hazırlandı. Bu standart çözeltilerin UV spektrumları 190-400 nm arasında çekildi ve maksimum verdiği dalga boylarındaki absorbans değerleri bulundu. Elde edilen absorbans değerleri kullanılarak çalışma yapıldı. Matematiksel olarak yapılan çalışmalarda, absorbans değerleri "y", konsantrasyon değerleri "x" alındı ve bu değerlerden yararlanılarak sıfırdan geçen doğru denklemleri türetildi. Yapılan çalışmalarda korelasyon katsayıları, r: 0.999 civarında bulundu. Böylece, her bileşik için Beer Lambert kanununa uygunluk olduğu görüldü.

Hazırlanan A çözeltisinden, UV spektrofotometresinde maksimum dalga boylarındaki absorbans değerleri bulundu. Bulunan değerler doğru denklemlerinde yerlerine konularak, oktanol tabakasındaki bileşik niteliği hesaplandı. 1/20 oranında hazırlanmış standart çözelti içindeki bileşik niceliğinden çıkarılarak, su tabakasına geçen bileşik miktarı bulundu. Bulunan nicelikler aşağıda verilen formüle uygulanarak, her bileşik için log P değerleri saptandı (Tablo 1).

$$
\log \mathbf{P}=\log \frac{\text { Oktanol tabakasındaki nicelik }}{\text { Su tabakasındaki nicelik }}
$$

Bileşiklerin $R_{M}$ Değerlerinin Saptanması: Uygulanan $R_{M}$ çalışmasında, sabit faz olarak, 1-oktanol/eter (5:05) (v/v) solvan sistemi ile doyurulmuş kiselgel $\mathrm{HF}_{254}$ kaplı cam plaklar kullanıldı. Hareketli faz olarak ise aseton/su (Tampon çözelti, pH: 7.8) kulla- 
nılarak, en iyi ayırımın 30:70 oranında hazırlanan solvanla olduğu görüldü $(9,14,15)$. Kullanılan 1-oktanol ve tampon çözeltinin hazırlanışı log $\mathbf{P}$ çalışmasında olduğu gibi yapıldı.

\section{Deneyin yapılışı:}

Camag ince tabaka yayıcısı ile $0.300 \mathrm{~mm}$ kalınlığında kiselgel $\mathrm{HF}_{254}$ ile kaplanan $20 \times 20 \mathrm{~cm}$ boyutlarındaki cam plaklar $105^{\circ} \mathrm{C}$ lik etüvde 1 saat tutuldu. 1-Oktanol/eter (5:05) (v/v) ihtiva eden kromatografi tankına konulan plaklar, 14 saat bu solvan sistemi ile doyuruldu. Bu sürenin sonunda plaklar tanktan çıkarıldı ve oda sıcaklı̆̆ında eteri uçuruldu.

Sentez edilen türevlerin, $1 \mathrm{mg} / \mathrm{ml}$ konsantrasyonda kloroform ile çözeltileri hazırlandı. Her türevin çözeltisinden 2 ug madde ihtiva edecek şekilde plak üzerine tatbik edildi. Daha sonra plak, oda sıcaklı̆̆ında, içinde aseton/su (Tampon çözelti, pH: 7.8) (30:70) (v/v) solvan sistemi bulunan kromatografi tankına konuldu. 5 Saatin sonunda solvan yeterli düzeye geldi ve plak çıkarılıp $105^{\circ} \mathrm{C}$ lik etüvde kurutuldu. Lekelerin belirlenmesi UV kullanılarak yapıldı. Her bileşiğin $R_{f}$ değeri ayrı ayrı hesaplandı. Bulunan değerler,

$$
\mathrm{R}_{\mathrm{M}}=\log \left(\frac{1}{\mathrm{Rf}}+1\right)
$$

formülünde yerine konularak, bileşiklerin $R_{M}$ değerleri saptandi. ( Tablo I).

\section{SONUÇ ve TARTIŞMA}

Bu çalışmada, sentezi daha önce yapılan, 2-sübstitüe-oksazolo (4,5-b) piridin türevleri ele alınmıştır (1). Oksazolopiridin türevlerinin antienflamatuvar etki göstermelerinden dolayı bu grup bileşiklerin histamin üzerine de etkili olabilecekleri düşünülmüştür. Özellikle n-hekzil türevinin uygulanan in vitro deneyde, histaminin kontraksiyonunu belirgin bir şekilde inhibe ettiği saptanmıştır.

Yapı-etki çalışmalarında, bileşiklerin fizikokimyasal parametreleri olarak $\log P$ ve $R_{M}$ değerleri ele alınmış ve bu hidrofobik parametreler, biyolojik etki ile bağdaştırılmıştır. 
Tablo I de bileşiklerin biyolojik etki sırasına göre log P ve RM değerlerinin dökümü verilmiştir.

Biyolojik etki-log $P$ ve biyolojk etki- $R_{M}$ arasındaki ilişkilerin doğru denklemlerindeki korelasyon katsayıları, sırasıyle 0.980 ve 0.966 olarak bulunmuştur. Bu sonuç, biyolojik etki ile adı geçen fizikokimyasal parametreler arasında bir ilişkinin varlığını göstermektedir.

Denklem 1, sentez edilen türevlerin log $P$ değerleri ile biyolojik etkiyi gösteren molar konsantrasyonlarının cologları arasındaki doğru denklemini vermektedir. (Veri sayısı: 12)

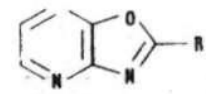

Tablo 1 Bileşiklerin biyolojik etki sirasına göre logP ve $R_{M}$ değerlerinin dökümü

\begin{tabular}{|c|c|c|c|c|c|c|c|c|}
\hline $\begin{array}{l}\text { Tür. } \\
\text { No. }\end{array}$ & $\mathbf{R}$ & $\begin{array}{l}\text { o.1 } \gamma_{\% \text { Hista- }} \\
\text { mini } \% 53 \\
\text { inh. erten } \\
\text { kons. }(\mathrm{mol} / \mathrm{ml})\end{array}$ & $\begin{array}{l}\text { Colog } \\
\text { kons. }\end{array}$ & $\begin{array}{l}\text { Sulu tabakada } \\
\text { kalan bileşik } \\
\text { miktarı (mg) }\end{array}$ & $\begin{array}{l}\text { Oktanollu } \\
\text { tabakada } \\
\text { kalan bileşik } \\
\text { miktari (mg) }\end{array}$ & $\log P$ & $\mathbf{R}_{\mathbf{r}}$ & $\mathbf{R}_{\mathrm{M}}$ \\
\hline I & $\mathrm{CH}_{3}$ & $80.4 \times 10^{-7}$ & 5.09 & 2.17 & 8.90 & 0.6129 & 0.6296 & -0.2503 \\
\hline I I & $\mathrm{C}_{2} \mathrm{H}_{5}$ & $58.1 \times 10^{-7}$ & 5.41 & 1.13 & 11.65 & 1.0132 & 0.5223 & -0.0387 \\
\hline IX & & $17.0 \times 10^{-7}$ & 5.76 & 0.73 & 12.52 & 1.2342 & 0.5111 & -0.0192 \\
\hline IV & i- $\mathrm{C}_{3} \mathbf{H}_{7}$ & $13.8 \times 10^{-7}$ & 5.85 & 0.57 & 15.28 & 1.3673 & 0.4274 & 0.1270 \\
\hline I I I & $\mathbf{n}-\mathbf{C}_{3} \mathbf{H}_{7}$ & $13.5 \times 10^{-7}$ & 5.66 & 0.52 & 12.37 & 1.3763 & 0.3984 & 0.1789 \\
\hline $\mathbf{X}$ & & $13.1 \times 10^{-7}$ & 5.87 & 0.33 & 8.67 & 1.4195 & 0.3550 & 0.2593 \\
\hline VI & $\mathrm{i}-\mathrm{C}_{4} \mathrm{H}_{9}$ & $11.5 \times 10^{-7}$ & 5.93 & 0.28 & 8.22 & 1.4677 & 0.2824 & 0.4050 \\
\hline $\mathbf{V}$ & & $8.7 \times 10^{-7}$ & 6.06 & 0.40 & 12.20 & 1.4842 & 0.2442 & 0.4906 \\
\hline XI & & 4.0 $\times 10^{-7}$ & 6.38 & 0.24 & 12.25 & 1.7079 & 0.2142 & 0.5644 \\
\hline VII & n-C & $3.3 \times 10^{-7}$ & 6.46 & 0.20 & 11.80 & 1.7708 & 0.1297 & 0.8267 \\
\hline XII & & $2.4 \times 10^{-7}$ & 6.61 & 0.18 & 10.99 & 1.7857 & 0.1214 & 0.8594 \\
\hline VI I I & n- $\mathrm{C}_{6} \mathrm{H}_{13}$ & $1.3 \times 10^{-7}$ & 6.85 & 0.13 & 12.05 & 1.9670 & 0.0671 & 1.1426 \\
\hline
\end{tabular}


Denklem 1, Colog $C=1.3279 \log \mathrm{P}+4.1067$

$$
\frac{\mathrm{n}}{12} \frac{\mathrm{r}}{0.9803} \frac{\mathrm{r}^{2}}{0.9610}
$$

$\mathrm{Bu}$ doğru denkleminde korelasyon katsayısı, $r=0.9803$ olarak, determinasyon katsayısı ise, $r^{2}=0.9610$ olarak bulunmuştur. Bu değerler bileşiklerin log $\mathrm{P}$ leri ile etkiyi gösteren molar konsantrasyonları arasında doğrusal bir bağıntı olduğunu göstermektedir.

Denklem 2, türevlerin $R_{M}$ değerleri ile biyolojik etkiyi gösteren molar konsantrasyonlarının cologları arasındaki doğru denklemini vermektedir. (Veri sayısı: 12)

$$
\begin{array}{ccc}
\text { Denklem 2, Colog } \mathrm{C}=1.1683 & \mathrm{R}_{\mathrm{M}}+5.5663 \\
\mathrm{n} & \mathrm{r} & \mathrm{r}^{2} \\
12 & 0.9668 & 0.9348
\end{array}
$$

$\mathrm{Bu}$ regrasyon sonuçlarında ise, korelasyon katsayısı, $r=0.9668$ olarak, determinasyon katsayısı, $r^{2}=0.9348$ olarak bulunmuştur. Bu değerler de bileşiklerin $R_{M}$ değerleri ile etkiyi gösteren molar konsantrasyonları arasında doğrusal bir bağıntı olduğunu kanıtlamaktadir.

Bileşiklerin $\log P$ ve $R_{M}$ değerleri tek tek incelendiğinde, küçük molekülllerin suda daha fazla, büyük moleküllerin ise daha az çözündüğ̈ görülmektedir. Bulgulara göre, histaminin kobay ile-umunda yaptığı kasılmayı büyük oranda inhibe ettiği belirlenen bu moleküllerin, yan zincirdeki karbon atomu sayısı arttıkça etkileri yükselmektedir. Türevlerin $\log P$ ve $R_{M}$ değerleri, düz zincirli moleküllerde, karşıtları olan halkalı ve dallanmış izomerlerine oranla daha yüksektir. Biyolojik etkininde aynı durumu gösterdiği dikkate alınırsa etki ile $\log$ ve $R_{M}$ parametreleri arasında net olarak bir ilişkinin bulunduğu ortaya çıkmaktadır. Bu ilişkiden yararlanılarak, bileşiklerin moleküler özelliklerinin değiştirilmesi ile ulaşılacak $\log P$ ve $R_{M}$ değerlerine göre etkili dozları hakkında önceden bir fikir edinilebilir.

Bu verilere göre, oksazolo (4,5-b) piridin türevlerinde 2. konuma bağlanan grupların biyolojik etki şiddetine katkısı, bu grupların 
yağda çözünürlüğü arttırıcı nitelikte olması ile doğru orantılıdır. Bu çalışmada, 2. konumda düz zincirli alkil grupları içeren bileşiklerden, metil, etil ve $n$-propilli türevler arasındaki log $\mathbf{P}$ ve biyolojik etki artışı farkları çok belirgin olduğu halde n-butil, n-pentil ve n-hekzilli türevlerde bu fark küçüktür. 2. Konumda sikloalkil içeren bileşikler, aynı sayıda karbon atomu bulunduran düz zincirli izomerleriyle karşılaştırıldığında, düz zincirli alkil taşıyan türevlerde etki daha şiddetlidir. Bu durum, düz zincirli alkil gruplarının bükülebilirliği nedeniyle halka üzerine katlanarak, halka ile etkileşmesi ve buna bağlı olarak da yağdaki çözünürlüğün artması sonucunu ortaya çıkarmaktadır. Ayrıca 2. konumda izopropil ve izobutil içeren türevlerin, aynı sayıda karbon atomu taşıyan düz zincirli izomerlere oranla daha az etkili olduğunun görülmesi de bu düşünceyi desteklemektedir. Diğer bir hidrofobik parametre olarak incelenen $R_{M}$ değerleri de aynı sonuçları ortaya koymaktadir.

Sonuç olarak, günümüze kadar üzerinde fizikokimyasal parametreler ele alınarak yapılan herhangi bir yapı-etki çalışmasına rastlanılmayan, oksazolo $(4,5-b)$ piridin türevleri üzerinde yapılan bu araştırma, oksazolopiridinlerin yapı-etki çalışmaları için bir başlangıç veya bir hareket noktası olabilir.

\section{LİTERATÜR}

1- Özden, S., Yalçın, İ., Özden, T., 2- Sübstitüeokzasolo (4, 5-b)- piridin Türevlerinin Sentez ve Yapı Açıklamaları, A.Ü.Ecz. Fak. Mec, 14, 53-66 (1984).

2- Shen, T.Y., Clark, R.L., Pessolano, A.A., Witzel, B., Lanza, T., U.S . Pat., 4. 038. 396, 26 Jul. 1977.

3- Shen, T.Y., Clark, R.L., Pessolano, A.A., Witzel, B., Lanza, T., The Pat. Off. London, 1.421.619, 11 Jun. 1973.

4- Özden, S., 3H-İmidazo (4,5-b) ve (4,5-c) piridinlerin 2-Alkil Sübstitüe Türevlerinde Nicel Yönden Yapı-Etki Bağdaştırılması Üzerinde Araştırmalar. A.Ü. Ecz. Fak. Doçentlik Tezi (1977).

5- Hoffman, C, Dorddly, A., The Pat. Off. London, 1.260.857, 19 Jan. 1972.

6- Hoffman, K., Hunger, A., Kehrle, J., Rossı, A., Deutsches Patentamt Auslegeschrift, 1.120.454, 28 Dezember 1961. 
7- Fraser, J., Tittensor, E., Oxazolopyridines and Oxazoloquinolines, J. Chem. Soc. 1781-4 (1956).

8- Ichler, O., Farah, A., Biological Determination of Histamine in Living Tissues and Body Fluids, Handbook of Experimental Pharmacology, Vol XVIII, 86 (1966).

9- Biagi, G., Barbara, A., Guerra, M., Cantielli-Rorti, G., and Fracasso, M., Relationship Between Activity and Rm Values of Sulfonamides, J. Med. Chem., 17, 28 (1974).

10- Bucher, K.H. and Draber, W., Structure-Activity Relationship of Photosynthesis Inhibition by NH-Acidic $\pi$-Excessive Heteroaromatics, Progr. Photosyn. Res., 3, 1777 (1969).

11- Fujita, T., Iwasa, J., Hansen, C., A New Substituent Constant Derived from Partition Coefficients, J. Amer. Chem. Soc, 86, 7175 (1964).

12- Kuo, K.H., Fukuto, T.R., Miller, T.A., Bruner, L.J., Blocking Membrane Conduc tance by Substituted Benzimidazolcs, Biophysical Journal, 16, 143 (1976).

13- Leo, A., Hansen, C., Elkıns, D., Partition Coefficients and Their Uses, Chem. Rev., 71, 525 (1971).

14- Biagi, G., Gandolfi, O., Guerra, M., Barbaro, A., Cantielli-Forti, G., RM Values of Phenols and Their Relationship with Log P Values and Activity, J. Med. Chem., 18, 658 (1975).

15- Tiscler, A.N., Thompson, F.M., Libertini, L.J., Calvin, M., Rifamycine Derivatives as Inhibitors of a Ribonucleic Acid Instructed Deoxyribonucleic Acid Polymerase Function Effect of Lipophilicty, J. Med. Chem., 17, 948 (1974). 